\title{
Role of ionotropic GABA, glutamate and glycine receptors in the tonic and reflex control of cardiac vagal outflow in the rat
}

\author{
Cara M Hildreth, Ann K Goodchild
}

\begin{abstract}
Background: Cardiac vagal preganglionic neurons (CVPN) are responsible for the tonic, reflex and respiratory modulation of heart rate (HR). Although CVPN receive GABAergic and glutamatergic inputs, likely involved in respiratory and reflex modulation of HR respectively, little else is known regarding the functions controlled by ionotropic inputs. Activation of g-protein coupled receptors (GPCR) alters these inputs, but the functional consequence is largely unknown. The present study aimed to delineate how ionotropic GABAergic, glycinergic and glutamatergic inputs contribute to the tonic and reflex control of HR and in particular determine which receptor subtypes were involved. Furthermore, we wished to establish how activation of the 5-HT 1 A GPCR affects tonic and reflex control of HR and what ionotropic interactions this might involve.

Results: Microinjection of the GABA antagonist picrotoxin into CVPN decreased HR but did not affect baroreflex bradycardia. The glycine antagonist strychnine did not alter HR or baroreflex bradycardia. Combined microinjection of the NMDA antagonist, MK801, and AMPA antagonist, CNQX, into CVPN evoked a small bradycardia and abolished baroreflex bradycardia. MK801 attenuated whereas CNQX abolished baroreceptor bradycardia. Control intravenous injections of the 5- $\mathrm{HT}_{1 \mathrm{~A}}$ agonist 8-OH-DPAT evoked a small bradycardia and potentiated baroreflex bradycardia. These effects were still observed following microinjection of picrotoxin but not strychnine into CVPN.

Conclusions: We conclude that activation of $G A B A_{A}$ receptors set the level of HR whereas AMPA to a greater extent than NMDA receptors elicit baroreflex changes in $\mathrm{HR}$. Furthermore, activation of $5-\mathrm{HT}_{1 \mathrm{~A}}$ receptors evokes bradycardia and enhances baroreflex changes in HR due to interactions with glycinergic neurons involving strychnine receptors. This study provides reference for future studies investigating how diseases alter neurochemical inputs to CVPN.
\end{abstract}

\section{Background}

Cardiac vagal preganglionic neurons (CVPN) are found predominantly in the nucleus ambiguus (NA) as well as dorsal motor nucleus of the vagus (DMNV) and in the intermediate zone (IZ) between these two nuclei [1-3]. Activation of CVPN has negative chronotropic, dromotropic and ionotropic effects on the heart [4-6] and the activity of these neurons is increased in response to baroreceptor stimulation [7-9] and inhibited during inspiration $[10,11]$.

Surprisingly little is known about the functional significance of inputs to CVPN mediated by either ionotropic

\footnotetext{
* Correspondence: ann.goodchild@asam.mq.edu.au
Australian School of Advanced Medicine, Macquarie University, Sydney,

* Correspondence: ann.goodchild@asam.mq.edu.au Australia
}

(c) 2010 Hildreth and Goodchild; licensee BioMed Central Ltd. This is an Open Access article distributed under the terms of the Creative Commons Attribution License (http://creativecommons.org/licenses/by/2.0), which permits unrestricted use, distribution, and reproduction in any medium, provided the original work is properly cited. substantial inputs from ionotropic receptors. Microinjection of the $\mathrm{GABA}_{\mathrm{A}}$ receptor antagonist bicuculline into the NA evokes a profound decrease in HR [12] demonstrating that there is a large GABAergic input to CVPN that plays a role in setting the tonic level of heart rate (HR). GABAergic inputs also appear to mediate the inspiratory related inhibition of CVPN and may play a role in generating respiratory sinus arrhythmia (RSA) [13]. Although glycine evokes tachycardia when injected unilaterally into the NA [14], the role of glycinergic inputs in both the tonic and reflex control of cardiac vagal outflow have not been systematically explored. Glutamatergic inputs, conversely, mediate baroreceptor dependent excitation of CVPN [7,15-17], however the 
glutamate receptor subtype(s) involved has yet to be determined.

The influence some GPCR have in regulating CVPN has been determined. For example, activation of serotonin-1a/7, dopamine, $\mu$-opioid or neurokinin-1 receptors within the NA decreases HR whereas activation of opioid-receptor like receptor-1 increases HR, demonstrating that activation of some GPCR can differentially alter the tonic level of HR [18-21]. The role of these GPCR, or for that matter others, however, in the reflex modulation of HR is not well understood. Systemic activation of serotonin-1A $\left(5-\mathrm{HT}_{1 \mathrm{~A}}\right)$ receptors potentiates baroreflex mediated bradycardia [22,23]. Central administration of the selective $5-\mathrm{HT}_{1 \mathrm{~A}}$ antagonist, WAY100635, attenuates baroreflex sensitivity suggesting a pivotal role for $5-\mathrm{HT}_{1 \mathrm{~A}}$ receptors in the maintenance of reflex cardiac vagal outflow [24]. Furthermore, $5-\mathrm{HT}_{1 \mathrm{~A}}$ receptor modulation of reflex cardiac vagal outflow is absent in the flinders sensitive line rat, an animal model of depression, which exhibits reduced BRS [23], thus highlighting the clinical importance of functional 5$\mathrm{HT}_{1 \mathrm{~A}}$ receptor control of cardiac vagal outflow.

How activation of 5-HT1A receptors produces bradycardia and enhances baroreflex bradycardia is unknown. Speculation suggests that as the $5-\mathrm{HT}_{1 \mathrm{~A}}$ receptor is an inhibitory GPCR, the mechanism must involve an interaction with inhibitory ionotropic inputs to CVPN [25]. In keeping with this hypothesis, application of 8-OHDPAT in vitro attenuates presynaptic GABAergic and glycinergic inputs to CVPN [26,27]; however the functional significance of these inputs is unknown. Whether or not the effects of $5-\mathrm{HT}_{1 \mathrm{~A}}$ activation on $\mathrm{HR}$ or BRS are mediated by GABAergic and/or glycinergic inhibition of CVPN in the ventrolateral medulla has not been investigated in vivo.

The initial aim of this study was to assess comprehensively, in the rat, the roles of $\mathrm{GABA}_{\mathrm{A}}$, strychnine-sensitive glycine and NMDA and AMPA receptors within regions of the medulla containing CVPN in the tonic and reflex control of HR. Secondly, we investigated if activation of the $5-\mathrm{HT}_{1 \mathrm{~A}}$ receptor evoked bradycardia and potentiation of baroreflex bradycardia was dependent upon GABAergic or glycinergic neurotransmission to CVPN.

\section{Methods}

All experiments were approved by Macquarie University animal ethics committee and conducted in accordance with the Australian Code of Practice for the Care and Use of Animals for Scientific Purposes. Animals were housed on a $12 \mathrm{~h}$ light dark cycle (lights on at $6 \mathrm{am}$ ) with food and water available ad libitum.

Adult male Sprague Dawley $(\mathrm{n}=34,300-600 \mathrm{~g})$ rats were anaesthetised with ethyl carbamate (urethane 1.3 g/kg ip; Sigma Aldrich Ltd.). Depth of anaesthesia was assessed regularly using reflex responses to tactile (corneal stroking) stimuli. Additional doses of urethane $(0.13 \mathrm{~g} / \mathrm{kg} \mathrm{IV})$ were administered as required. The right femoral artery and vein were cannulated to enable recording of arterial pressure (AP) and to administer drugs, respectively. A tracheotomy was performed. Rectal temperature was monitored and maintained at $37^{\circ} \mathrm{C}$, using a thermostatically controlled electric blanket (Harvard Apparatus, USA) and an infrared-heating source. Animals were then placed in a stereotaxic frame and artificially ventilated with oxygen enriched room air. Peak expired $\mathrm{CO}_{2}$ was continuously monitored and maintained between $3.5-4.5 \%$. A laminectomy was performed at $\mathrm{C} 8$, the spinal cord transected, and an occipital craniotomy was performed to expose the dorsal surface of the medulla.

\section{Experimental Protocol Location of CVPN}

In all animals, sites were located within the ventrolateral medulla from which vagally mediated bradycardia was evoked by $50 \mathrm{nl}$ microinjections of L-glutamate (100 $\mathrm{mM}$; Sigma Aldrich Ltd.). Microinjections of L-glutamate were made in a region encompassing 1.4-2.0 mm lateral to the midline, $0-1.2 \mathrm{~mm}$ rostral to the calamus scriptorius and between $1.5-3.5 \mathrm{~mm}$ ventral to the dorsal surface of the medulla. Tracks were separated by at least $0.3 \mathrm{~mm}$ and sites within a track by $0.5 \mathrm{~mm}$ or more. At each injection site the change in HR and/or presence of atrioventricular (AV) block, determined by the absence of QRS complex on the ECG waveform, were determined. The location of CVPN was identified as a site where a bradycardia $>50 \mathrm{bpm}$ or AV block was evoked by microinjection of L-glutamate. In each experiment, 4 sites ( 2 per side) where the largest bradycardia or AV block concurrent with bradycardia were evoked, were targeted in order to cover the entire rostro-caudal extent of CVPN. At the end of each experiment these sites were marked with pontamine sky blue and the rat euthanased with potassium chloride $(3 \mathrm{M})$. The medulla was removed and placed in $4 \%$ formaldehyde in phosphate buffer $(0.1 \mathrm{M})$. Coronal sections (100 $\mu \mathrm{m})$ were cut with a vibrating microtome and stained with cresyl violet for histological analysis.

\section{Effect of spinal cord transection on basal cardiovascular parameters}

In 7 animals the effect of spinal cord transection on HR, mean AP (MAP) and BRS was examined. MAP and HR were calculated over an $80 \mathrm{sec}$ period immediately prior to spinal cord transection and after the peak fall in AP was reached and maintained at a steady level (roughly 30-45 mins post transection). Baroreceptor function curves were generated using bolus injections of 
phenylephrine $(10 \mu \mathrm{g} / \mathrm{kg}$ in $0.1 \mathrm{ml}$ saline IV) prior to spinal cord transection and after the peak fall in AP, and BRS was then calculated.

\section{Drug microinjections}

Twenty-five animals received drug microinjections into cardioinhibitory sites of the medulla. Once the two most cardiac responsive sites per side (i.e. four sites in total) were located, the drug to be tested (as indicated below) was microinjected into each of the sites $(100 \mathrm{nl}$ per injection, 2 injections per side) identified. The criteria for a cardiac responsive site were bradycardia exceeding $50 \mathrm{bpm}$ or AV block and that the 4 sites covered the rostro-caudal extent of CVPN and were $\sim 600 \mu \mathrm{m}$ apart.

Animals either received two $100 \mathrm{nl}$ bilateral microinjections of muscimol $\left(\mathrm{GABA}_{\mathrm{A}}\right.$ agonist, $100 \mathrm{mM} \mathrm{n}=4$; Sigma-Aldrich Inc.), picrotoxin $\left(\mathrm{GABA}_{\mathrm{A}}\right.$ receptor antagonist, $2 \mathrm{mM} \mathrm{n}=6[28]$ ), bicuculline methiodide $\left(\mathrm{GABA}_{\mathrm{A}}\right.$ antagonist, $0.4 \mathrm{mM} \mathrm{n}=4$ [29]; Sigma-Aldrich Inc.), strychnine hydrochloride (strychnine sensitive glycine receptor antagonist, $3 \mathrm{mM} \mathrm{n}=4$ [30]; SigmaAldrich Inc.), MK801 (NMDA receptor antagonist, 5 $\mathrm{mM} \mathrm{n}=4$ [31]; Sigma-Aldrich Inc.) or CNQX (AMPA receptor antagonist, $2 \mathrm{mM} \mathrm{n}=3$ [32]; Research Biomedical International). Prior to drug microinjection and again at nadir cardiac response, baroreceptor function was assessed using changes in AP in response to bolus injections of phenylephrine $(10 \mu \mathrm{g} / \mathrm{kg}$ in $0.1 \mathrm{ml} \mathrm{IV})$. HR was calculated over three 80 second segments prior to drug microinjection and at the peak HR response. In rats receiving MK801 $(\mathrm{n}=4)$, CNQX $(2 \mathrm{mM})$ was then microinjected into the vicinity of CVPN following examination of baroreceptor function in order to examine effects of combined NMDA and AMPA receptor blockade on cardiac vagal function. In rats receiving microinjection of picrotoxin or strychnine, 8-OH-DPAT $(0.1$ $\mathrm{mg} / \mathrm{kg} \mathrm{IV)} \mathrm{was} \mathrm{administered} \mathrm{and} \mathrm{baroreceptor} \mathrm{curves}$ generated again. In a separate cohort of rats, $8-\mathrm{OH}-$ DPAT $(0.1 \mathrm{mg} / \mathrm{kg} \mathrm{IV}, \mathrm{n}=9)$ was administered and baroreceptor function curves generated at the peak cardiovascular response.

\section{Data Analysis}

Data was acquired using CED1401 analogue-digital converter hardware and analysed off-line using Spike 2 software v. 6.2 (both from CED, Cambridge, UK).

\section{BRS}

The index method was used to calculate BRS. The index method calculates BRS as the ratio between the decrease in $\mathrm{HR}$ and increase in MAP $(\triangle \mathrm{HR} / \triangle \mathrm{MAP})$ induced by phenylephrine. BRS estimated using this method does not differ from BRS estimated using linear regression analysis [33]. BRS calculated from each replicate curve generated was averaged to give one final BRS estimate.

\section{Statistical Analysis}

All data are presented as mean \pm SEM. Paired or ratio $t$ tests were used to determine if each treatment affected HR or BRS. One-way ANOVA was used to compare effect of 8-OH-DPAT on HR under control conditions versus following picrotoxin or strychnine. $P<0.05$ was considered significant (GraphPad Prism v5).

\section{Results}

Effect of lower cervical spinal cord transection on basal cardiovascular variables

In 7 animals, the effect of transection of the spinal cord at the 8th cervical segment on MAP, HR and baroreflex function was determined. Spinal cord transection evoked a profound fall in MAP $(98.2 \pm 4.2 \mathrm{v} 60.2 \pm 4.6 \mathrm{mmHg}$ $P<0.001)$ and reduced resting HR $(344 \pm 15$ v $302 \pm$ $10 \mathrm{bpm} P<0.05)$. This hypotensive condition caused by reduced sympathetic activity also ensures that the baroreceptors are fully unloaded. Baroreflex mediated changes in $\mathrm{HR}$, in response to induced increases in AP with phenylephrine, were unaffected by spinal cord transection and both the gain $(0.76 \pm 0.18 \times 0.43 \pm 0.10 \mathrm{bpm} /$ $\mathrm{mmHg} P=0.0955)$ and range $(45 \pm 10 \mathrm{v} 37 \pm 9 \mathrm{bpm} P$ $=0.4637)$ of the baroreflex was not altered.

\section{Location and verification of CVPN sites in the medulla}

The medulla was mapped by glutamate microinjection to determine the sites from which a vagally mediated bradycardia could be evoked. Vehicle injection into these regions did not affect resting HR (340 \pm 5 vs. 337 $\pm 10 \mathrm{bpm}$ before vs. after vehicle injection, $P=0.6595 \mathrm{n}$ $=3$ and as previously described $[19,20,34])$. To verify that the sites targeted contained CVPN and that the entire rostro-caudal distribution of CVPN in the medulla could be targeted with two bilateral microinjections, bilateral microinjections of the $\mathrm{GABA}_{\mathrm{A}}$ agonist muscimol were made in 4 animals. The effects of muscimol on HR and baroreflex function are shown in Figure 1A. HR rose to $356 \pm 15 \mathrm{bpm}$ from $282 \pm 3 \mathrm{bpm}(P<$ 0.05 , Figure $1 \mathrm{~B})$ and this was associated with a reduction in BRS $(0.66 \pm 0.21 \mathrm{bpm} / \mathrm{mmHg}$ v $0.10 \pm 0.02 \mathrm{bpm} /$ $\mathrm{mmHg}, P<0.05$, Figure $1 \mathrm{C}$ ), effectively abolishing baroreflex control of HR. A similar effect on the baroreflex has been described previously [35]. This confirms that the sites identified here are the source of cardiac vagal outflow and that the majority of CVPN could be targeted with two bilateral microinjections.

Role of ionotropic $G_{A B A_{A}}$ and strychnine sensitive glycine receptors in areas of the medulla containing CVPN in the tonic and baroreflex control of HR

The effects of bilateral microinjections of the $\mathrm{GABA}_{\mathrm{A}}$ antagonist picrotoxin on $\mathrm{HR}$ and baroreflex function are 
A.
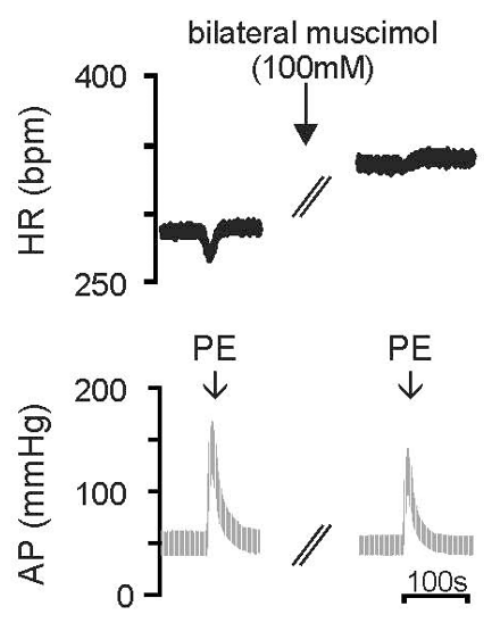

B.

C.
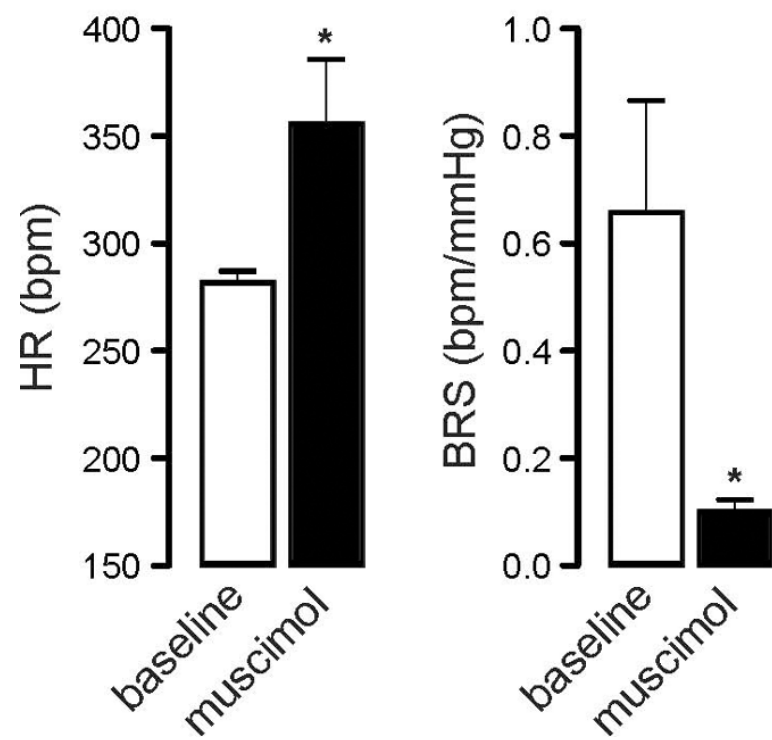

Figure 1 Verification that dual bilateral microinjections in the ventral medulla inhibits cardiac vagal outflow. A representative trace is provided in panel $\mathrm{A}$ showing that microinjection of muscimol $(100 \mathrm{mM}, 100 \mathrm{nl})$ into four regions of the medulla where bradycardia greater than $50 \mathrm{bpm}$ was evoked by prior microinjection of L-glutamate $(100 \mathrm{mM}, 50 \mathrm{nl})$ increases resting heart rate (HR) and prevents baroreflex mediated bradycardia. Grouped data $(n=4)$ shows that microinjection of muscimol into these four sites evokes a large increase in HR (panel B) and dramatically reduces baroreflex sensitivity (BRS, panel C). ${ }^{*} P<0.05$.

shown in Figure 2A. Bilateral picrotoxin elicited a profound reduction in HR (from $300 \pm 4 \mathrm{bpm}$ to $176 \pm 13$ bpm, $P<0.01$, Figure 2D); however, in contrast to activation of $\mathrm{GABA}_{\mathrm{A}}$ receptors (Figure 1D), blockade of $\mathrm{GABA}_{\mathrm{A}}$ receptors did not alter BRS (Figure 2E). Bilateral microinjection of bicuculline, another $\mathrm{GABA}_{\mathrm{A}}$ antagonist, as illustrated in Figure 2B, also evoked a profound decrease in HR $(335 \pm 11 \mathrm{v} 185 \pm 30 \mathrm{bpm}$, control v bicuculline $P<0.01 \mathrm{n}=4$ ) decreasing HR to a level similar to that seen following picrotoxin $(P=0.76)$. However bicuculline consistently evoked arrhythmias possibly resulting from the blockade of after-hyperpolarisation potentials $\left(\mathrm{I}_{\mathrm{AHP}}\right)$ arising due to the blockade of SK channels [36]. As a result BRS could not be analysed.

The effect of bilateral microinjection of strychnine on $\mathrm{HR}$ and baroreflex function is shown in Figure 2C. Inhibition of strychnine-sensitive glycine receptors had no effect on resting HR $(296 \pm 27 \mathrm{bpm}$ v $272 \pm 13 \mathrm{bpm} P$ $=0.2051$ Figure 2D) or BRS $(0.44 \pm 0.17 \mathrm{bpm} / \mathrm{mmHg} \mathrm{v}$ $0.49 \pm 0.13 \mathrm{bpm} / \mathrm{mmHg}, P=0.60$ Figure $2 \mathrm{E})$.

Role of ionotropic glutamate receptors in areas of the medulla containing CVPN in the tonic and baroreflex control of $\mathrm{HR}$

The effects of bilateral inhibition of NMDA or AMPA receptors in medullary regions containing CVPN on HR and baroreflex function are shown in Figure 3A and 3B respectively. Blockade of NMDA receptors with MK801 or AMPA receptors with CNQX did not change resting HR (Figure 3D). BRS, however, was reduced by approximately $40 \%$ in response to blockade of NMDA receptors $(0.49 \pm 0.06$ v $0.29 \pm 0.06 \mathrm{bpm} / \mathrm{mmHg}, P<0.05$ Figure $3 \mathrm{E})$ and $83 \%$ in response to blockade of AMPA receptors $(0.40 \pm 0.11 \mathrm{v} 0.07 \pm 0.01 \mathrm{bpm} / \mathrm{mmHg}, P<0.05$ Figure $3 \mathrm{E})$.

The effects of combined AMPA/NMDA receptor blockade in the region containing CVPN on HR and baroreflex function are shown in Figure 3C. A small reduction in resting HR (306 $\pm 16 \mathrm{bpm}$ v $284 \pm 17 \mathrm{bpm}$ $P<0.05$, Figure 3D) was observed and BRS was reduced by approximately $85 \%(0.40 \pm 0.11 \vee 0.06 \pm 0.01 \mathrm{bpm} /$ $\mathrm{mmHg}, P<0.05$ Figure 3E). BRS following combined AMPA/NMDA receptor blockade was similar to that following AMPA receptor blockade alone $(P=0.33)$.

Role of GABAergic and glycinergic neurotransmission in regions of the medulla containing CVPN in cardio-vagal responses to $5-\mathrm{HT}_{1 \mathrm{~A}}$ receptor activation

The effect of intravenous administration of 8-OH-DPAT $(0.1 \mathrm{mg} / \mathrm{kg})$ on HR and baroreflex function is illustrated in Figure 4A. Activation of $5-\mathrm{HT}_{1 \mathrm{~A}}$ receptors with 8OH-DPAT evoked a small but significant decrease in resting HR (from $310 \pm 17 \mathrm{bpm}$ control to $296 \pm 15$ bpm, $P<0.05$ Figure $4 \mathrm{D}$ ) and a $40 \%$ increase in BRS (from $0.49 \pm 0.07 \mathrm{bpm} / \mathrm{mmHg}$ to $0.73 \pm 0.14 \mathrm{bpm} /$ $\mathrm{mmHg}, P<0.05$ Figure 4E) as previously described [23].

The effect of intravenous 8-OH-DPAT on HR and baroreflex function following microinjection of picrotoxin or strychnine is shown in Figure $4 \mathrm{~B}$ and $4 \mathrm{C}$ respectively. Following microinjection of picrotoxin, 


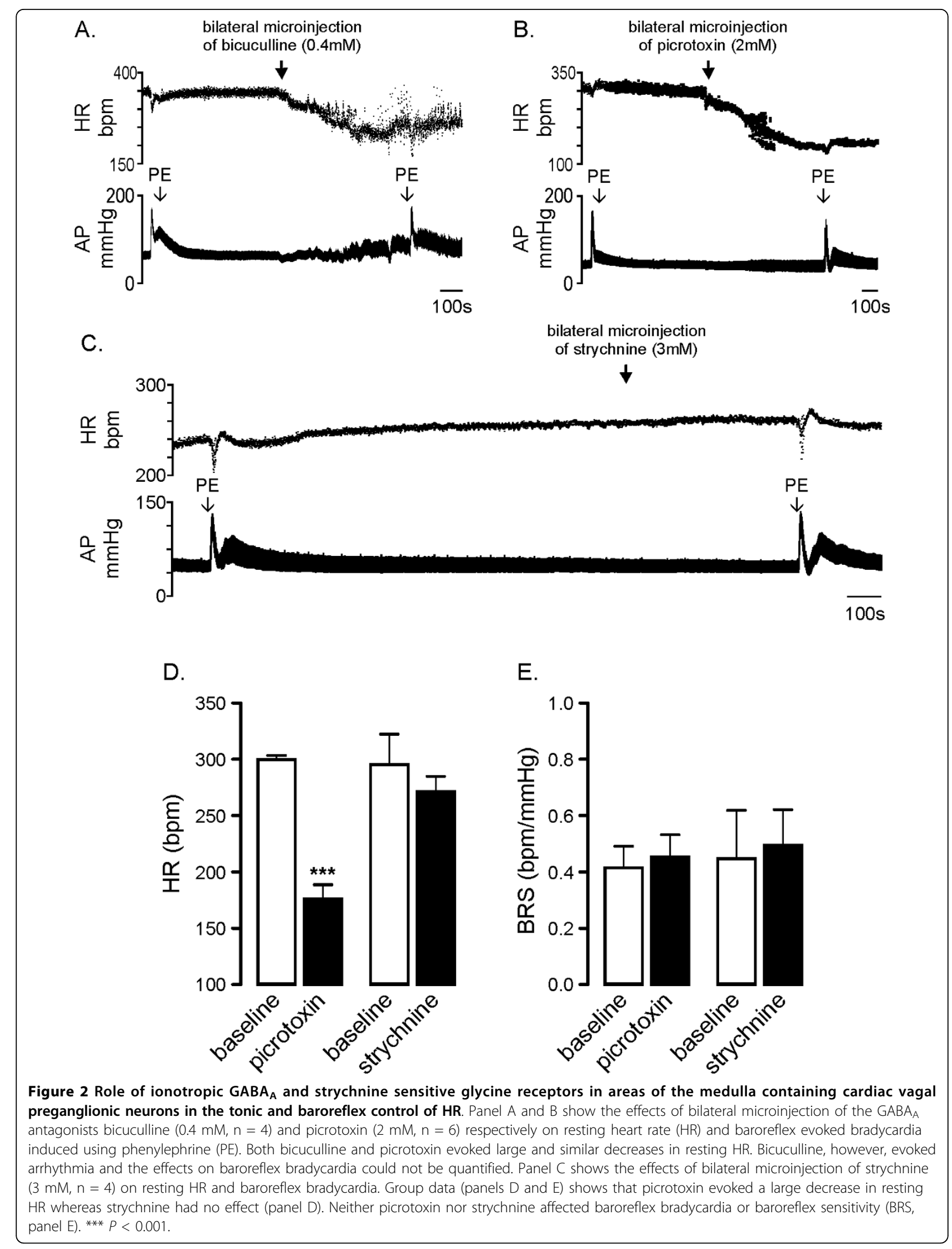




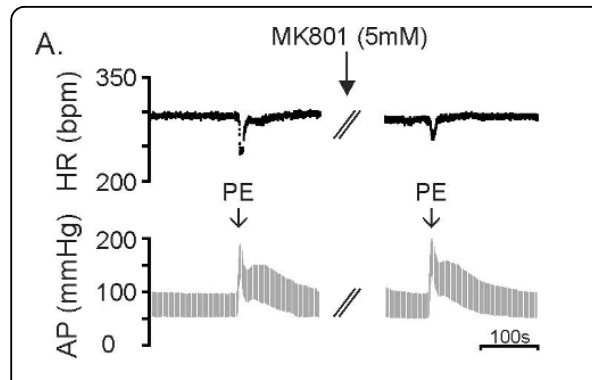

D.

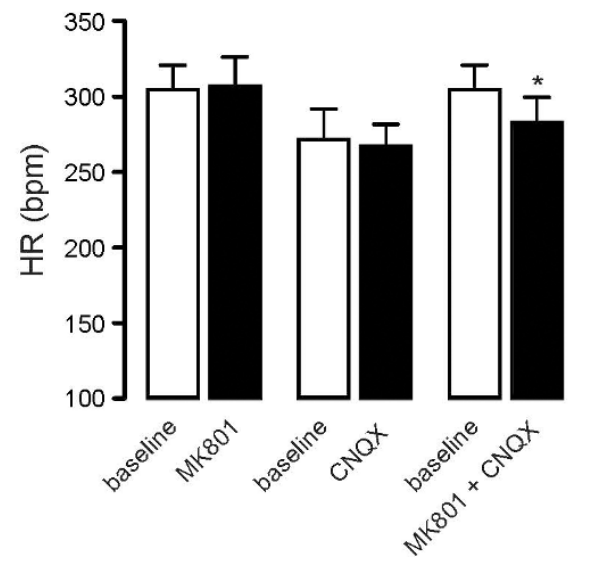

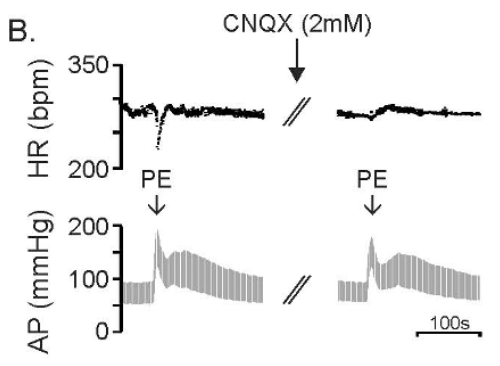

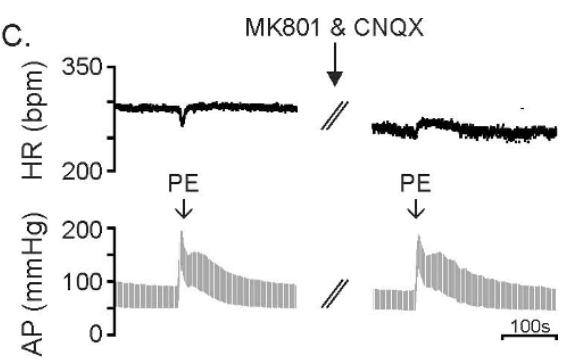

E.

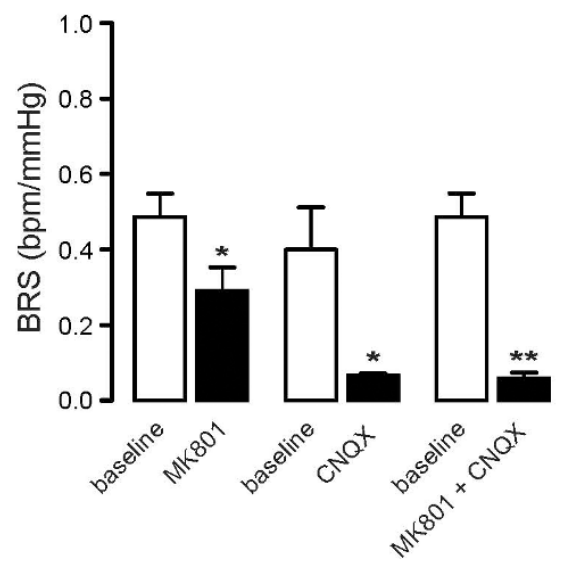

Figure 3 Role of ionotropic glutamate receptors in areas of the medulla containing CVPN in the tonic and baroreflex control of HR. Panel A illustrates the effects of bilateral microinjection of the NMDA antagonist MK801 (5 mM, n=4), panel B illustrates the effects of bilateral microinjection of the AMPA antagonist $\mathrm{CNQX}(2 \mathrm{mM}, \mathrm{n}=3)$ and panel $\mathrm{C}$ illustrates the effects of bilateral microinjection of $C N Q X$ following MK801 $(n=4)$ on resting heart rate $(H R)$ and baroreflex bradycardia. Panel $D$ illustrates the effects of these antagonists on resting HR. Neither MK801 nor CNQX alone altered resting HR; however, combined microinjection of these antagonists evoked a small but significant decrease in resting HR. In panel $E$ the effect of these antagonists on baroreflex function are shown. Microinjection of MK801 evoked a modest decrease in baroreflex sensitivity (BRS) whereas microinjection of CNQX dramatically reduced BRS and abolished all baroreflex function. Combined microinjection of MK801 and CNQX reduced BRS to levels similar to that observed following microinjection of CNQX alone. ${ }^{*} P<0.05$, ${ }^{* *} P<$ 0.01 .

intravenous administration of $8-\mathrm{OH}-\mathrm{DPAT}$ still decreased resting HR (from $205 \pm 13 \mathrm{bpm}$ to $181 \pm 14$ bpm, $P<0.01$ Figure 4D) and increased BRS (from 0.45 $\pm 0.08 \mathrm{bpm} / \mathrm{mmHg}$ to $0.59 \pm 0.09 \mathrm{bpm} / \mathrm{mmHg}, P<0.05$ Figure 4E). Following microinjection of strychnine, intravenous administration of 8-OH-DPAT $(0.1 \mathrm{mg} / \mathrm{kg})$ no longer evoked a decrease in HR $(283 \pm 15 \mathrm{bpm} v$ $285 \pm 13 \mathrm{bpm} P=0.75$ Figure 4D) or an increase in BRS $(0.49 \pm 0.13 \mathrm{bpm} / \mathrm{mmHg}$ v $0.41 \pm 0.10 \mathrm{bpm} /$ $\mathrm{mmHg}, P=0.29$ Figure $4 \mathrm{E})$. The inhibitory actions of 8 $\mathrm{OH}-\mathrm{DPAT}$ on HR were unaffected by prior microinjection of picrotoxin but abolished through prior microinjection of strychnine $(-13 \pm 5 \mathrm{bpm}$ vs. $-23 \pm 6 \mathrm{bpm}$ vs. 2 $\pm 5 \mathrm{bpm}$ control vs. picrotoxin vs. strychnine $P<0.05)$.

\section{Discussion}

The major findings of the present study are that in regions of the brain containing CVPN: 1 . Activation of $\mathrm{GABA}_{\mathrm{A}}$ receptors is required to set the resting level of HR; 2. Baroreflex mediated bradycardia is dependent upon activation of AMPA receptors to a greater extent than NMDA receptors 3. Strychnine sensitive glycine receptors are not involved in the tonic or reflex control of HR but their activation is required to enable the bradycardiac and baroreflex facilitating effects of $5-\mathrm{HT}_{1 \mathrm{~A}}$ receptor activation.

\section{Role of ionotropic GABA and glycine receptors in regions} of the medulla containing CVPN in the tonic and reflex control of $\mathrm{HR}$

We have shown that $\mathrm{GABA}_{\mathrm{A}}$ receptors, but not strychnine sensitive glycine receptors, are required for setting the level of $\mathrm{HR}$. That $\mathrm{GABA}_{\mathrm{A}}$ receptors are vital for setting the tonic level of vagal outflow to the heart is well established and our findings support the notion that CVPN receive a substantial GABAergic input [12,35]. The bradycardia evoked following bilateral microinjection of either picrotoxin or bicuculline is likely due to blockade of postsynaptic $\mathrm{GABA}_{\mathrm{A}}$ receptors on CVPN as focal application of picrotoxin blocks inhibitory 


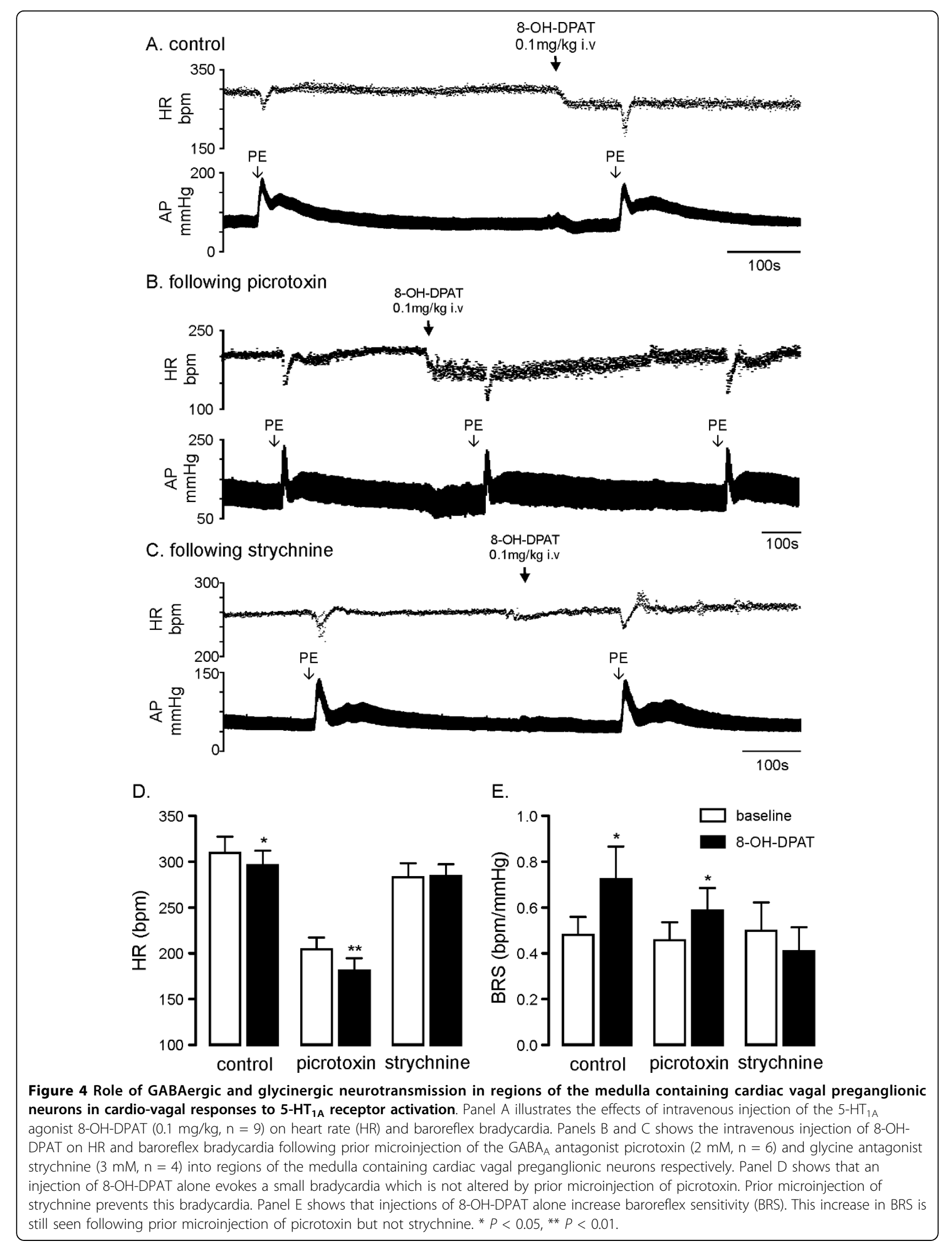


postsynaptic currents in CVPN [13,37]. Our finding that bilateral microinjection of strychnine does not alter resting $\mathrm{HR}$ is in contrast with previous reports where unilateral microinjection of strychnine into the NA decreased resting HR suggesting a role for strychnine sensitive glycine receptors in the control of HR at least in cats [12]. Nevertheless, in rats, microinjection of strychnine does not affect the tachycardic response to microinjection of glycine in cardioinhibitory sites of the medulla [14]. Together with our results this suggests that strychnine-sensitive glycine receptors are not involved in the tonic control of cardiac vagal outflow in the rat.

While the role of $\mathrm{GABA}_{\mathrm{A}}$ and strychnine sensitive glycine receptors in the tonic control of $H R$ has been investigated previously, how these receptors are involved in evoking reflex changes in HR has not. It has been hypothesised that disinhibiting CVPN through inhibition of GABAergic or glycinergic inputs to CVPN can improve BRS through the facilitation of excitatory inputs to CVPN $[23,38,39]$. We tested this and showed that bilateral microinjection of picrotoxin or strychnine did not alter BRS. This demonstrates for the first time that neither $\mathrm{GABA}_{\mathrm{A}}$ nor strychnine sensitive glycine receptors are required for the baroreflex activation of cardiac vagal outflow, at least in regions of the medulla containing CVPN.

Role of ionotropic glutamate receptors in regions of the medulla containing CVPN in the tonic and reflex control of $\mathrm{HR}$

Activation of ionotropic glutamate receptors, which are found on the soma and dendrites of CVPN [40], with Lglutamate produces a decrease in HR (as seen here to identify CVPN and previously $[18,20,34])$. However, combined blockade of NMDA and AMPA receptors did not evoke an expected increase in HR, but paradoxically a bradycardia. This confirms the study of Guyenet et al [15] who observed bradycardia following microinjection of kynurenic acid into the region of the NA. We extended these findings by showing that blockade of either NMDA or AMPA receptors alone did not evoke any change in HR suggesting that there is not a substantial tonic ionotropic glutamatergic input to CVPN. In light of the small bradycardia evoked by combined receptor blockade, it is possible that there is some tonic glutamatergic control of inhibitory inputs to CVPN. Glutamatergic modulation, involving both NMDA and AMPA receptors, of GABAergic inputs to CVPN in the DMNV but not NA has been described previously [41]. It remains possible that glutamatergic regulation of glycinergic inputs may exist in the NA.

Baroreflex mediated changes in parasympathetic outflow to the heart occur via glutamatergic inputs from the nucleus tractus solitarius (NTS) to cardiac vagal preganglionic neurons (CVPN) located principally in the nucleus ambiguus (NA). Several lines of evidence support this: Stimulation of the baroreflex in vivo evokes a reflex increase in CVPN activity which correlates with the reflex bradycardia evoked [7]; Microinjection kynurenic acid, a non-specific glutamate antagonist, into the region of the NA prevents vagally mediated baroreflex bradycardia [15]; Electrical stimulation of depressor sites within the NTS increases CVPN unit activity in vivo [17]; Stimulation of the NTS in vitro evokes excitatory postsynaptic currents in CVPN which are inhibited by combined blockade of NMDA and AMPA receptors [16].

While there is substantial evidence to indicate that glutamatergic inputs to CVPN are necessary for the generation of baroreflex bradycardia, the receptor subtype(s) responsible for eliciting these reflex changes is unknown. Both NMDA and AMPA receptors are located on the soma and dendrites of CVPN [40]. In the present study, inhibition of NMDA receptors modestly attenuated BRS whereas blockade of AMPA receptors completely abolished baroreflex control of HR. The reduction in BRS evoked by CNQX alone was similar to that following combined NMDA/AMPA receptor blockade. Thus, the integrity of AMPA receptors within CVPN alone is critical to the baroreflex activation of cardiac vagal outflow whereas NMDA receptors play a more minor role. This contrasts with the responses obtained in other vagal motoneurons in the NA, where NMDA receptors mediate the effects evoked by stimulation of the NTS [42].

Our findings also contrast with those some of those described within other medullary regions of the baroreflex arc. In the NTS some report that baroreflex neurotransmission is dependent upon NMDA receptor activation [43] and others, non-NMDA receptor activation [44]. Nevertheless, the majority report that both receptor subtypes are required for full expression of the baroreceptor reflex [45-49]. The caudal ventrolateral medulla, which also receives baroreceptor input from the NTS, is excited by activation of both AMPA and NMDA receptors [50]. A greater dependence on AMPA over NMDA receptors for the full expression of baroreceptor mediated bradycardia therefore appears to be unique to the vagal outflow of the baroreflex.

\section{Role of ionotropic GABAergic and glycinergic neurotransmission within regions of the medulla containing CVPN in the cardio-vagal responses to $5-\mathrm{HT}_{1 \mathrm{~A}}$ receptor activation}

We have confirmed previous findings which demonstrate that systemic administration of $8-\mathrm{OH}-\mathrm{DPAT}$ results in a vagally mediated bradycardia and 
potentiation in baroreflex mediated bradycardia [22,23]. We have then extended these findings to determine the central mechanisms responsible for this 8-OH-DPAT evoked potentiation in reflex bradycardia.

8-OH-DPAT is an agonist at both $5-\mathrm{HT}_{1 \mathrm{~A}}$ and $5-\mathrm{HT}_{7}$ receptors [51], although the actions at the $5-\mathrm{HT}_{1 \mathrm{~A}}$ receptor are presumed responsible for the potentiation in reflex vagal outflow. Kellett and others [24] demonstrated that intracisternal administration of WAY100635 , the $5-\mathrm{HT}_{1 \mathrm{~A}}$ selective antagonist, attenuates baroreflex mediated bradycardia indicating that $5-\mathrm{HT}_{1 \mathrm{~A}}$ receptors in the medulla are responsible for the facilitation of baroreflex bradycardia evoked by 8 -OH-DPAT. Wang and Ramage [25] further showed that iontophoresis of WAY-100635 onto CVPN attenuates the increase in activity of these neurons in response to stimulation of pulmonary $\mathrm{C}$ fibres.

The most logical explanation for the 8-OH-DPAT mediated facilitation of baroreflex bradycardia is through inhibition of GABAergic or glycinergic inputs to CVPN. In support of this hypothesis, in slice preparation, application of 8-OH-DPAT inhibits both GABAergic and glycinergic inputs to CVPN [26,27]. To confirm the physiological relevance of these findings we blocked $\mathrm{GABA}_{\mathrm{A}}$ receptors or strychnine-sensitive glycine receptor in the vicinity of CVPN and examined the response of systemic 8-OH-DPAT on the tonic and reflex bradycardia evoked. We found that intravenous 8-OH-DPAT administration evoked bradycardia and potentiated BRS in the presence of $\mathrm{GABA}_{\mathrm{A}}$ receptor blockade whereas 8$\mathrm{OH}$-DPAT failed to evoke a response when strychnine sensitive glycine receptors were antagonised. It is unlikely that the ability of 8-OH-DPAT to improve BRS in the presence of picrotoxin is related to the HR lowering effects of picrotoxin. An inverse relationship does exist between resting HR and BRS, such that the lower the HR the greater the BRS [52]; however, if the ability for 8-OH-DPAT to improve BRS in the presence of picrotoxin was solely due to a HR lowering effect of picrotoxin then BRS should have improved following microinjection of picrotoxin. As this was not the case, this indicates that 8-OH-DPAT improves BRS independent of the resting level of HR. Furthermore, our findings indicate that the bradycardiac and baroreflex enhancing effects of 8-OH-DPAT are dependent upon functional glycinergic neurotransmission in the vicinity of CVPN.

The finding that 8-OH-DPAT acts via a glycinergic mechanism was surprising as microinjection of strychnine did not affect $\mathrm{HR}$ or BRS. As $5-\mathrm{HT}_{1 \mathrm{~A}}$ receptors are purported to be tonically involved in the reflex activation of CVPN [22,24], we expected that if 8-OH-DPAT were acting on glycinergic neurons directly innervating CVPN then strychnine would mimic the effects of 8-
OH-DPAT. While we cannot reconcile this perplexing finding, a previous in vitro study indicated that glycinergic inputs to CVPN are more sensitive to 8-OH-DPAT than GABAergic inputs providing some support for our findings. The location of the $5-\mathrm{HT}_{1 \mathrm{~A}}$ receptor with respect to both $\mathrm{CVPN}$ and glycinergic input is unknown. Our current hypothesis is that the $5-\mathrm{HT}_{1 \mathrm{~A}}$ receptor is located upstream of a glycinergic input to CVPN.

\section{Conclusions}

Diseases including hypertension, depression and kidney failure are associated with impaired function of vagal inputs to the heart [53-55]. Understanding how neurochemicals control cardiac vagal function is essential to determining what can go wrong in disease. Until now central neurochemical inputs to CVPN responsible for the tonic and reflex control of HR have been poorly investigated. Here we present a comprehensive investigation of the role of ionotropic GABAergic, glycinergic and glutamatergic inputs in the tonic and reflex control of HR. We also provide a mechanism by which activation of $5-\mathrm{HT}_{1 \mathrm{~A}}$ receptors can improve vagal outflow to the heart. This is an important contribution as activation of $5-\mathrm{HT}_{1 \mathrm{~A}}$ receptors does not improve baroreflex function in rodent models of depression suggesting that the interaction between $5-\mathrm{HT}_{1 \mathrm{~A}}$ receptors and glycinergic neurons may be involved in the aetiology of abnormal vagal control of HR in depression [23]. This study enhances our understanding of neural control of the heart and will provide a reference point for future studies examining central mechanisms responsible for impaired cardiac vagal control in disease.

\section{Acknowledgements}

Work in the authors' laboratory is supported by the NHMRC (457068), Heart Foundation (G095434), Hillcrest Foundation (Perpetual), Hunter Medical Research Institute and Macquarie University.

\section{Authors' contributions}

$\mathrm{CMH}$ carried out the experiments, analysed the data and drafted the manuscript. AKG conceived, designed and coordinated the study and critically revised the manuscript. Both authors read and approved the final manuscript.

Received: 25 March 2010 Accepted: 13 October 2010 Published: 13 October 2010

\section{References}

1. Nosaka S, Yamamoto T, Yasunaga K: Localization of vagal cardioinhibitory preganglionic neurons with rat brain stem. J Comp Neurol 1979, 186(1):79-92.

2. Corbett EK, Batten TF, Kaye JC, Deuchars J, McWilliam PN: Labelling of rat vagal preganglionic neurones by carbocyanine dye Dil applied to the heart. Neuroreport 1999, 10(6):1177-1181.

3. Izzo PN, Deuchars J, Spyer KM: Localization of cardiac vagal preganglionic motoneurones in the rat: immunocytochemical evidence of synaptic inputs containing 5-hydroxytryptamine. J Comp Neurol 1993, 327(4):572-583. 
4. Thompson ME, Felsten G, Yavorsky J, Natelson BH: Differential effect of stimulation of nucleus ambiguus on atrial and ventricular rates. American Journal of Physiology 1987, 253(1):R150-R157.

5. Geis G, Wurster R: Cardiac responses during stimulation of the dorsal motor nucleus and nucleus ambiguus in the cat. Circ Res 1980, 46(5):606-611.

6. Sampaio K, Mauad H, Ford TW, Spyer KM: Chronotropic and dromotropic effects of L-glutamate ( $\mathrm{L}$-glu) injected into the rat nucleus ambiguus (NA). Auton Neurosci 2000, 62.

7. McAllen RM, Spyer KM: The baroreceptor input to cardiac vagal motoneurones. J Physiol 1978, 282:365-374.

8. Nosaka S, Yasunaga K, Tamai S: Vagal cardiac preganglionic neurons: distribution, cell types, and reflex discharges. Am J Physiol 1982, 243(1): R92-98.

9. Rentero N, Cividjian A, Trevaks D, Pequignot JM, Quintin L, McAllen RM: Activity patterns of cardiac vagal motoneurons in rat nucleus ambiguus. Am J Physiol Regul Integr Comp Physiol 2002, 283(6):R1327-1334.

10. Gilbey MP, Jordan D, Richter DW, Spyer KM: Synaptic mechanisms involved in the inspiratory modulation of vagal cardio-inhibitory neurones in the cat. J Physiol 1984, 356:65-78.

11. McAllen RM, Spyer KM: The location of cardiac vagal preganglionic motoneurones in the medulla of the cat. J Physiol 1976, 258(1):187-204.

12. DiMicco JA, Gale K, Hamilton B, Gillis RA: GABA receptor control of parasympathetic outflow to heart: characterization and brainstemlocalization. Science 1979, 204(4397):1106-1109.

13. Neff RA, Wang J, Baxi S, Evans C, Mendelowitz D: Respiratory sinus arrhythmia: endogenous activation of nicotinic receptors mediates respiratory modulation of brainstem cardioinhibitory parasympathetic neurons. Circ Res 2003, 93(6):565-572.

14. Chitravanshi VC, Agarwal SK, Calaresu FR: Microinjection of glycine into the nucleus ambiguus elicits tachycardia in spinal rats. Brain Res 1991, 566(1-2):290-294.

15. Guyenet PG, Filtz TM, Donaldson SR: Role of excitatory amino acids in rat vagal and sympathetic baroreflexes. Brain Res 1987, 407(2):272-284.

16. Neff RA, Mihalevich M, Mendelowitz D: Stimulation of NTS activates NMDA and non-NMDA receptors in rat cardiac vagal neurons in the nucleus ambiguus. Brain Res 1998, 792(2):277-282

17. Agarwal SK, Calaresu FR: Electrical stimulation of nucleus tractus solitarius excites vagal preganglionic cardiomotor neurons of the nucleus ambiguus in rats. Brain Res 1992, 574(1-2):320-324

18. Agarwal SK, Calaresu FR: Enkephalins, substance $P$ and acetylcholine microinjected into the nucleus ambiguus elicit vagal bradycardia in rats. Brain Res 1991, 563(1-2):203-208.

19. Chitravanshi VC, Calaresu FR: Additive effects of dopamine and 8-OHDPAT microinjected into the nucleus ambiguus in eliciting vagal bradycardia in rats. J Auton Nerv Syst 1992, 41(1-2):121-127.

20. Chitravanshi VC, Sapru HN: Microinjections of nociceptin into the nucleus ambiguus elicit tachycardia in the rat. Brain Res 2005, 1051(1-2):199-204.

21. Massari VJ, Johnson TA, Gillis RA, Gatti PJ: What are the roles of substance $P$ and neurokinin-1 receptors in the control of negative chronotropic or negative dromotropic vagal motoneurons? A physiological and ultrastructural analysis. Brain Res 1996, 715(1-2):197-207.

22. Skinner MR, Ramage AG, Jordan D: Modulation of reflexly evoked vagal bradycardias by central 5-HT1A receptors in anaesthetized rabbits. $\mathrm{Br} J$ Pharmacol 2002, 137(6):861-873.

23. Hildreth CM, Padley JR, Pilowsky PM, Goodchild AK: Impaired serotonergic regulation of heart rate may underlie reduced baroreflex sensitivity in an animal model of depression. Am J Physiol Heart Circ Physiol 2008, 294(1):H474-480.

24. Kellett DO, Ramage AG, Jordan D: Central 5-HT7 receptors are critical for reflex activation of cardiac vagal drive in anaesthetized rats. J Physiol 2005, 563(Pt 1):319-331.

25. Wang $Y$, Ramage AG: The role of central $5-\mathrm{HT}(1 \mathrm{~A})$ receptors in the control of B-fibre cardiac and bronchoconstrictor vagal preganglionic neurones in anaesthetized cats. J Physiol 2001, 536(Pt 3):753-767.

26. Wang $X$, Dergacheva $O$, Kamendi H, Gorini C, Mendelowitz D: 5Hydroxytryptamine $1 \mathrm{~A} / 7$ and 4alpha receptors differentially prevent opioid-induced inhibition of brain stem cardiorespiratory function. Hypertension 2007, 50(2):368-376.

27. Chen $\mathrm{YH}$, Hou LL, Wang JJ: 5-HT1A/7 receptor agonist excites cardiac vagal neurons via inhibition of both GABAergic and glycinergic inputs. Acta Pharmacol Sin 2008, 29(5):529-538.
28. Mallet N, Le Moine C, Charpier S, Gonon F: Feedforward inhibition of projection neurons by fast-spiking GABA interneurons in the rat striatum in vivo. J Neurosci 2005, 25(15):3857-3869.

29. Ciriello J, Roder S: GABAergic effects on the depressor responses elicited by stimulation of central nucleus of the amygdala. Am J Physiol Heart Circ Physiol 1999, 276(1):H242-247

30. Mueller PJ, Foley CM, Vogl HW, Hay M, Hasser EM: Cardiovascular response to a group III mGluR agonist in NTS requires NMDA receptors. Am J Physiol Regul Integr Comp Physiol 2005, 289(1):R198-208.

31. Wang W-Z, Yuan W-J, Su D-F: Blockade of N-methyl-aspartate receptors within the rostral ventrolateral medulla antagonizes clonidine-induced cardiovascular effects. Autonomic Neuroscience 2003, 109(1-2):21-28.

32. Miyawaki T, Minson J, Arnolda L, Chalmers J, Llewellyn-Smith I, Pilowsky P: Role of excitatory amino acid receptors in cardiorespiratory coupling in ventrolateral medulla. Am J Physiol 1996, 271(5 Pt 2):R1221-1230.

33. Farah VM, Moreira ED, Pires MD, Irigoyen MC, Krieger EM: Comparison of three methods for the determination of baroreflex sensitivity in conscious rats. Braz J Med Biol Res 1999, 32(3):361-369.

34. Chitravanshi VC, Bhatt S, Sapru HN: Microinjections of alpha-melanocyte stimulating hormone into the nucleus ambiguus of the rat elicit vagally mediated bradycardia. Am J Physiol Regul Integr Comp Physiol 2009, 296(5):1402-1411.

35. Williford DJ, Hamilton BL, Gillis RA: Evidence that a GABAergic mechanism at nucleus ambiguus influences reflex-induced vagal activity. Brain Res 1980, 193(2):584-588

36. Debarbieux F, Brunton J, Charpak S: Effect of bicuculline on thalamic activity: a direct blockade of IAHP in reticularis neurons. J Neurophysiol 1998, 79(6):2911-2918.

37. Wang J, Irnaten M, Mendelowitz D: Characteristics of spontaneous and evoked GABAergic synaptic currents in cardiac vagal neurons in rats. Brain Res 2001, 889(1-2):78-83.

38. Ramage AG, Villalon CM: 5-hydroxytryptamine and cardiovascular regulation. Trends Pharmacol Sci 2008, 29(9):472-481.

39. Jordan D: Vagal control of the heart: central serotonergic (5-HT) mechanisms. Exp Physiol 2005, 90(2):175-181.

40. Corbett EK, Saha S, Deuchars J, McWilliam PN, Batten TF: Ionotropic glutamate receptor subunit immunoreactivity of vagal preganglionic neurones projecting to the rat heart. Auton Neurosci 2003, 105(2):105-117.

41. Wang JJ, Chen YH, Li KY, Sun FY: GABAergic neurons innervating the preganglionic cardiac vagal neurons in the dorsal motor nucleus receive tonic glutamatergic control. Sheng Li Xue Bao 2005, 57(6):761-765.

42. Wang YT, Bieger D, Neuman RS: Activation of NMDA receptors is necessary for fast information transfer at brainstem vagal motoneurons. Brain Res 1991, 567(2):260-266.

43. Frigero $M$, Bonagamba $L G$, Machado $B H$ : The gain of the baroreflex bradycardia is reduced by microinjection of NMDA receptor antagonists into the nucleus tractus solitarii of awake rats. J Auton Nerv Syst 2000, 79(1):28-33.

44. Gordon FJ, Leone C: Non-NMDA receptors in the nucleus of the tractus solitarius play the predominant role in mediating aortic baroreceptor reflexes. Brain Res 1991, 568(1-2):319-322.

45. Sartor DM, Verberne AJ: The role of NMDA and non-NMDA receptors in the NTS in mediating three distinct sympathoinhibitory reflexes. Naunyn Schmiedebergs Arch Pharmacol 2007, 376(4):241-252.

46. Ohta H, Talman WT: Both NMDA and non-NMDA receptors in the NTS participate in the baroreceptor reflex in rats. Am J Physiol 1994, 267(4 Pt 2):R1065-1070

47. Viard E, Sapru HN: Carotid baroreflex in the rat: role of glutamate receptors in the medial subnucleus of the solitary tract. Neuroscience 2004, 126(3):785-794

48. Kubo T, Kihara M: Unilateral blockade of excitatory amino acid receptors in the nucleus tractus solitarii produces an inhibition of baroreflexes in rats. Naunyn Schmiedebergs Arch Pharmacol 1991, 343(3):317-322.

49. Zhang J, Mifflin SW: Differential roles for NMDA and non-NMDA receptor subtypes in baroreceptor afferent integration in the nucleus of the solitary tract of the rat. J Physiol 1998, 511(Pt 3):733-745.

50. Miyawaki T, Suzuki S, Minson J, Arnolda L, Chalmers J, Llewellyn-Smith I, Pilowsky P: Role of AMPA/kainate receptors in transmission of the sympathetic baroreflex in rat CVLM. Am J Physiol 1997, 272(3 Pt 2): R800-812. 
51. Hedlund PB, Kelly L, Mazur C, Lovenberg T, Sutcliffe JG, Bonaventure P: 8OH-DPAT acts on both 5-HT1A and 5-HT7 receptors to induce hypothermia in rodents. Eur J Pharmacol 2004, 487(1-3):125-132.

52. Hesse C, Charkoudian N, Liu Z, Joyner MJ, Eisenach JH: Baroreflex sensitivity inversely correlates with ambulatory blood pressure in healthy normotensive humans. Hypertension 2007, 50(1):41-46.

53. Parati G, Di Rienzo M, Bertinieri G, Pomidossi G, Casadei R, Groppelli A Pedotti A, Zanchetti A, Mancia G: Evaluation of the baroreceptor-heart rate reflex by 24 -hour intra-arterial blood pressure monitoring in humans. Hypertension 1988, 12(2):214-222.

54. Steinberg AA, Mars RL, Goldman DS, Percy RF: Effect of end-stage renal disease on decreased heart rate variability. Am J Cardiol 1998, 82(9):1156-1158, A1110.

55. Carney RM, Blumenthal JA, Stein PK, Watkins L, Catellier D, Berkman LF, Czajkowski SM, O'Connor C, Stone PH, Freedland KE: Depression, heart rate variability, and acute myocardial infarction. Circulation 2001, 104(17):2024-2028.

doi:10.1186/1471-2202-11-128

Cite this article as: Hildreth and Goodchild: Role of ionotropic GABA, glutamate and glycine receptors in the tonic and reflex control of cardiac vagal outflow in the rat. BMC Neuroscience 2010 11:128.

\section{Submit your next manuscript to BioMed Central} and take full advantage of:

- Convenient online submission

- Thorough peer review

- No space constraints or color figure charges

- Immediate publication on acceptance

- Inclusion in PubMed, CAS, Scopus and Google Scholar

- Research which is freely available for redistribution

Submit your manuscript at www.biomedcentral.com/submit 